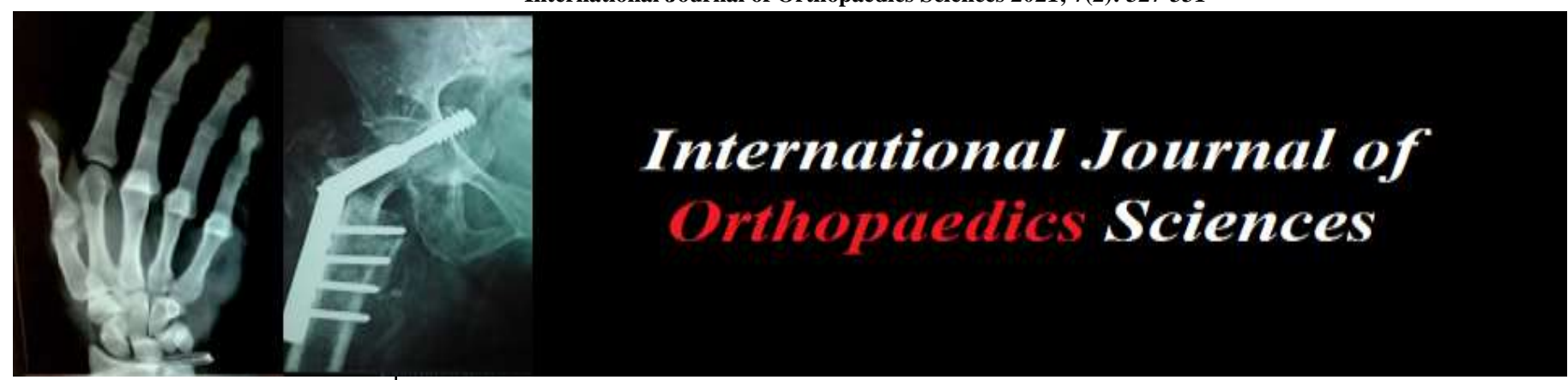

E-ISSN: 2395-1958

P-ISSN: 2706-6630

IJOS 2021; 7(2): 327-331

(C) 2021 IJOS

www.orthopaper.com

Received: 04-02-2021

Accepted: 07-03-2021

Anchul Kumar Pahadiya Department of Orthopaedics, SMS Hospital, Jaipur,

Rajasthan, India

Narendra Joshi

Department of Orthopaedics, SMS Hospital, Jaipur,

Rajasthan, India

Rakesh Dhukia

Department of Orthopaedics, SMS Hospital, Jaipur,

Rajasthan, India

Vishal Shekhawat

Department of Orthopaedics,

SMS Hospital, Jaipur,

Rajasthan, India

Deependra Singh

Department of Orthopaedics,

SMS Hospital, Jaipur,

Rajasthan, India

\section{Comparative study of distal femoral locking compression plate and tens nail versus lateral distal femur plate in management of distal femur fracture cases}

\author{
Anchul Kumar Pahadiya, Narendra Joshi, Rakesh Dhukia, Vishal \\ Shekhawat and Deependra Singh
}

DOI: https://doi.org/10.22271/ortho.2021.v7.i2e.2647

\section{Abstract}

Background: The fracture of distal femur are often unstable and comminuted and as difficult to treat. The incidence of complications in these fracture are relatively high . The purpose of our study was aimed to compare functional outcome between both column fixations by using distal femoral locking compression pate on lateral side and then using TENS nail on medial side to obtain support of medial column versus lateral distal femoral plate.

Methods: We have included 80 patients with distal femur fracture with intercondylar extension in our study. We have treated 40 patients with distal femoral locking compression plate and support of medial wall with TENS nail and 40 patients with distal femoral locking compression plate. There were sixty six males and fourteen females. The average age of the patients was $39.08 \pm 11.95$ years. All the patients were operated between 3 to 9 days. All patients were followed up at 2th, 6th, 10th weeks, 3 month and 6 month regularly and evaluated for fracture healing, Clinical union was defined as a painless fracture site during full weight bearing. Radiological union was defined as bridging trabeculation across the fracture site on three of four cortices. The final outcome was assessed according to schatzker and Lambert scoring system.

Results: The result was excellent in twelve, good in fifteen, fair in ten and poor in one in DFLCP with TENS nail group according to schatzker and Lambert scoring system. The result was excellent in eight, good in twelve, fair in twelve and poor in five in DFLCP group according to schatzker and Lambert scoring system. The average time to Union was 17.7 weeks in DFLCP with TENS nail group and 19.9 weeks in DFLCP group. Complications include superficial wound infection in three patients, secondary osteoarthritis in 17 patients and varus angulation in three patients in DFLCP with TENS nail group. In DFLCP group varus angulation was in eleven patients.

Conclusions: The use of TENS nail for medial femoral defect along with distal femoral locking compression plate may eliminate the need of plate on medial side. The varus angulation that occurs with defect is decreased and additional long incision and operative time is avoided.

Keywords: TENS nail, varus angulation, distal femur fracture with intercondylar extension, medial femoral defect

\section{Introduction}

Distal femoral fractures are fractures within the distal $15 \mathrm{~cm}$ of the femur, which includes the metaphysis, epiphysis and the articular surface ${ }^{[1]}$. According to Muller, this fracture is classified according to their location and pattern in three types, type A (extraarticular), type B (condylar or partial articular), and type C (bicondylar or complete articular) ${ }^{[2]}$. Surgical fixation has consistently demonstrated better outcomes than nonsurgical management [3]. Definitive treatment of distal femoral fractures requires maintenance or restoration of distal femoral alignment to preserve the function of the extremity. Additionally, early knee motion is central to the management of distal femoral fracture. Knee stiffness and loss of range of motion (ROM) may develop with immobilization ${ }^{[4,5]}$.

Distal femur fractures can be treated by traditional plating techniques (blade plate, Dynamic Condylar Screw, non-locking condylar buttress plate), antegrade nailing fixation, retrograde
Corresponding Author:

Department of Orthopaedics,

SMS Hospital, Jaipur,

Rajasthan, India 
nailing, sub muscular locked internal fixation and external fixation. However, as the complexity of fractures needing treatment has changed from simple extra- articular supracondylar types to inter-condylar and metaphyseal comminuted types, these implants may not be ideal. Double plating, and more recently, locked plating techniques have been advocated. However, with double plating there is often extensive soft tissue stripping on both sides of the femur, resulting in reduced blood supply and potential non-union and failure of the implants ${ }^{[6]}$.

Here we conducted a prospective comparative study to evaluate the efficacy of both column fixation by using distal femoral locking compression plate on lateral side and then using TENS nail on medial side to obtain support of medial column and prevent varus angulation.

\section{Methods}

\section{Study design and duration}

A prospective comparative randomized interventional study conducted on 80 patients in Department of Orthopedics, SMS hospital Jaipur from April 2018 to June 2019. The study included 80 patients with distal femur fracture (type $\mathrm{C}$ of $\mathrm{AO}$ classification) who presented in Trauma Centre, SMS Hospital. Prior approval from the institutional ethical committee was obtained. All patients were explained clearly about the study and informed consent was obtained from each of them.

Sample size was calculated 37 subjects for each of two groups at $\alpha$ (alpha) error 0.05 and power $80 \%$ assuming difference in means to be detected in. Time for radiological union in distal femoral fractures treated with distal femoral locking compression plates and .with comminuted medial wall with condylar buttress plate and support of medial wall with TENS nail 2 weeks with SD of 3 weeks (as per seed article). So for the study purpose 40 distal femoral fracture will be taken for each of two groups.

\section{Methodology}

This was a prospective comparative randomized interventional study conducted on 80 patients in Department of Orthopedics, SMS Jaipur. Our aim was tocompare functional outcome between both column fixations by using distal femoral locking compression pate on lateral side and then using TENS nail on medial side to obtain support of medial column versus lateral distal femoral plate in distal femoral intercondylar fracture. Distal femoral fracture was fixed with DFLCP with TENS nail in 40 patients and in 40 patients fracture was fixed with DFLCP. Preoperative evaluation and X-Ray was done. Patients were then asked to follow up at 2nd week, 6th week, 10thwk, 2 months, 6 months postoperatively after then till the last follow up. Functional outcome was evaluated in the form of time for radiological union, weight bearing and range of motion.

\section{Inclusion criteria}

All the patients with 18-60 years with intercondylar fracture (type c of AO classification) of femur was included in study.

Patients consenting was to be included in study.

\section{Exclusion criteria}

Patients with pathological fracture Patients unfit for surgery Patients with associated injury or previous injury or neurovascular injury to the affected limb.

Polytraumatized patient Grade 3 of gustilo Anderson classification of open fracture.
The collected data was compiled in MS Excel 10 sheet as Master Sheet.

- Quantitative variables were expressed as mean and SD.

- Qualitative variables were expressed as frequencies and percent.

- Appropriate statistical tests were applied to obtain results.

- A significance level of $\mathrm{P}<0.05$ was used in all tests

\section{Results}

Table 1: Age distribution of study subjects

\begin{tabular}{|c|c|c|}
\hline Age group (years) & N & Percentage \\
\hline$<20$ & 03 & 3.75 \\
\hline $20-29$ & 16 & 20 \\
\hline $30-39$ & 21 & 26.3 \\
\hline $40-49$ & 18 & 22.5 \\
\hline $50-60$ & 22 & 27.5 \\
\hline Total & 80 & 100 \\
\hline Mean \pm SD & \multicolumn{2}{|c|}{$39.08 \pm 11.95$} \\
\hline
\end{tabular}

Most of the patients were in the range of $30-49$ years $(48.8 \%)$. $23.75 \%$ were in the range of $18-29$ years and $27.5 \%$ were in the range of 50-60 yrs.

Table 2: Distribution of study subjects as per gender

\begin{tabular}{|c|c|c|}
\hline Gender & $\mathbf{N}$ & Percentage \\
\hline Male & 66 & 82.5 \\
\hline Female & 14 & 17.5 \\
\hline Total & 80 & 100 \\
\hline
\end{tabular}

In our study $82.5 \%$ were males and $17.5 \%$ were females.

Table 3: Distribution of study subjects as per mode of injury

\begin{tabular}{|c|c|c|}
\hline Mode of injury & N & Percentage \\
\hline RTA & 73 & 91.3 \\
\hline FFH & 05 & 6.2 \\
\hline Assault & 02 & 2.5 \\
\hline Total & 80 & 100 \\
\hline
\end{tabular}

In $91.3 \%$ of the patients, the most common mode of injury was RTA (road traffic accidents). $6.2 \%$ patients had history of fall and $2.5 \%$ had history of assault.

Table 4: Distribution of fracture as per AO classification

\begin{tabular}{|c|c|c|}
\hline AO classification & $\mathbf{N}$ & Percentage \\
\hline $\mathrm{C} 1$ & 17 & 21.3 \\
\hline $\mathrm{C} 2$ & 36 & 45 \\
\hline $\mathrm{C} 3$ & 27 & 33.7 \\
\hline Total & 80 & 100 \\
\hline
\end{tabular}

Most patients were in $\mathrm{C} 2$ group as per AO classification

Table 4: Comparison of partial weight bearing duration post-surgery among the surgical groups

\begin{tabular}{|c|c|c|c|c|c|c|}
\hline \multirow{2}{*}{$\begin{array}{c}\text { Partial } \\
\text { weight } \\
\text { bearing } \\
\text { (Weeks) }\end{array}$} & $\begin{array}{c}\text { DFLCP } \\
\text { with TENS } \\
\text { Nail }\end{array}$ & $\%$ & DFLCP & \% & N & $\%$ \\
\hline$<7$ & 08 & 21.0 & 05 & 13.5 & 13 & 17.3 \\
\hline $7-9$ & 20 & 52.6 & 12 & 32.4 & 32 & 42.7 \\
\hline $10-12$ & 10 & 26.4 & 17 & 45.9 & 27 & 36.0 \\
\hline $13-15$ & 00 & 00.0 & 03 & 08.2 & 03 & 04.0 \\
\hline Total & 38 & 100 & 37 & 100 & 75 & 100 \\
\hline
\end{tabular}

In our study we started partial weight bearing in 7-9 weeks in $52.6 \%$ in DFLCP with TENS nail group and in DFLCP group we started partial weight bearing in 10-12 weeks in $45.9 \%$. 
Table 6: Comparison of full weight bearing duration post surgery among the surgical groups

\begin{tabular}{|c|c|c|c|c|c|c|}
\hline \multirow{2}{*}{$\begin{array}{c}\text { Full weight } \\
\text { bearing } \\
\text { (Weeks) }\end{array}$} & $\begin{array}{c}\text { DFLCP } \\
\text { with TENS } \\
\text { Nail }\end{array}$ & $\%$ & DFLCP & $\%$ & $\mathbf{N}$ & $\%$ \\
\hline $11-14$ & 03 & 07.9 & 01 & 02.9 & 04 & 05.5 \\
\hline $15-18$ & 18 & 47.3 & 11 & 32.3 & 29 & 40.3 \\
\hline $19-22$ & 12 & 31.6 & 09 & 26.5 & 21 & 29.2 \\
\hline $23-26$ & 03 & 07.9 & 08 & 23.5 & 11 & 15.3 \\
\hline$>26$ & 02 & 05.3 & 05 & 14.8 & 07 & 09.7 \\
\hline Total & 38 & 100 & 34 & 100 & 72 & 100 \\
\hline
\end{tabular}

Chi-square $=6.474$ with 4 degree of freedom; $\mathrm{P}=0.179$ (NS)

In our study in DFLCP with TENS nail group we started full weight bearing in $78.9 \%$ patients within $15-22$ weeks and in $54.1 \%$ within $15-22$ weeks in DFLCP group. Three patients went to non-union so not advised to bear full weight and three patients lost follow up in DFLCP group. Two patients lost follow up in DFLCP with TENS nail group.
Table 7: Comparison of time of union (weeks) post surgery among the surgical groups

\begin{tabular}{|c|c|c|c|c|c|c|}
\hline \multirow{2}{*}{$\begin{array}{c}\text { Union } \\
\text { time } \\
\text { (Weeks) }\end{array}$} & $\begin{array}{c}|c| \\
\text { DFLCP } \\
\text { with TENS } \\
\text { Nail }\end{array}$ & $\%$ & DFLCP & \% & $\mathbf{N}$ & $\%$ \\
\hline$\leq 15$ & 08 & 21.0 & 05 & 14.7 & 13 & 18.0 \\
\hline $16-20$ & 22 & 57.9 & 16 & 47.0 & 38 & 52.8 \\
\hline $21-25$ & 05 & 13.2 & 07 & 20.6 & 12 & 16.7 \\
\hline $26-30$ & 03 & 07.9 & 06 & 17.7 & 09 & 12.5 \\
\hline Total & 38 & 100 & 34 & 100 & 72 & 100 \\
\hline
\end{tabular}

Chi-square $=2.759$ with 3 degree of freedom; $\mathrm{P}=0.454$ (NS)

In our study in DFLCP with TENS nail group $78.9 \%$ fractures were united in $<15$ to 20 weeks and in DFLCP group $56.7 \%$ fractures were united in $<15$ to 20 weeks. Average time to Union was 17.7 weeks in DFLCP with TENS nail group and 19.9 weeks in DFLCP group.

Table 8: Comparison of post-operative complications among the surgical groups

\begin{tabular}{|c|c|c|c|c|c|c|c|}
\hline \multirow{2}{*}{ Complications } & \multicolumn{3}{|c|}{ Surgery } & \multicolumn{2}{c|}{ Total } & P value \\
\cline { 2 - 8 } & DFLCP with TENS Nail & $\mathbf{\%}$ & DFLCP & $\mathbf{\%}$ & $\mathbf{N}$ & $\mathbf{\%}$ & \\
\hline Nonunion & 00 & 00.0 & 03 & 07.5 & 03 & 03.7 & $0.07(\mathrm{NS})$ \\
\hline Infection & 03 & 07.5 & 03 & 07.5 & 06 & 07.5 & - \\
\hline Varus Angulation & 03 & 07.5 & 11 & 27.5 & 14 & 17.5 & $0.01(\mathrm{~S})$ \\
\hline Limb length discrepancy & 13 & 32.5 & 18 & 45.0 & 31 & 38.8 & $0.27(\mathrm{NS})$ \\
\hline Secondary osteoarthritis & 17 & 42.5 & 17 & 42.5 & 34 & 42.5 & - \\
\hline
\end{tabular}

Non union was not seen in DFLCP with TENS nail group.

In our study varus angulation was significant where fixation done with DFLCP.

Table 9: Comparison of highest degree of range of motion post 6 months of surgery among the surgical groups

\begin{tabular}{|c|c|c|c|c|c|c|}
\hline \multirow{2}{*}{ Highest degree of range of motion } & \multicolumn{3}{|c|}{ Surgery } & \multicolumn{2}{c|}{ Total } \\
\cline { 2 - 7 } & $\begin{array}{c}\text { DFLCP } \\
\text { with TENS Nail (N=38) }\end{array}$ & $\mathbf{\%}$ & DFLCP (N=37) & \multirow{\%}{*}{ N(75) } & \% \\
\hline $90-100$ & 03 & 07.9 & 04 & 10.9 & 07 & 09.4 \\
\hline $100-110$ & 05 & 13.1 & 10 & 27.0 & 15 & 20.0 \\
\hline $110-120$ & 15 & 39.5 & 09 & 24.3 & 24 & 32.0 \\
\hline $120-130$ & 10 & 26.3 & 10 & 27.0 & 20 & 26.6 \\
\hline$\geq 130$ & 05 & 13.2 & 04 & 10.8 & 09 & 12.0 \\
\hline
\end{tabular}

Chi-square $=3.408$ with 4 degree of freedom; $\mathrm{P}=0.492$ (NS)

In our study range of motion was increased after TENS nail is removed in DFLCP with TENS nail group.

Table 10: Comparison among the surgical groups in terms of Schatzker and Lambert Grade

\begin{tabular}{|c|c|c|c|c|c|c|}
\hline \multirow{2}{*}{ Schatzker and Lambert Grade) } & \multicolumn{3}{|c|}{ Surgery } & \multicolumn{2}{c|}{ Total } \\
\cline { 2 - 6 } & DFLCP with TENS Nail & $\mathbf{\%}$ & DFLCP & $\mathbf{\%}$ & $\mathbf{N}$ & $\mathbf{\%}$ \\
\hline Excellent & 11 & 28.9 & 09 & 24.3 & 20 & 26.7 \\
\hline Good & 17 & 44.7 & 13 & 35.1 & 30 & 40.0 \\
\hline Fair & 09 & 23.7 & 11 & 29.8 & 20 & 26.7 \\
\hline Poor & 01 & 02.7 & 04 & 10.8 & 05 & 06.6 \\
\hline Total & 38 & 100 & 37 & 100 & 75 & 100 \\
\hline
\end{tabular}

Chi-square $=2.72$ with 3 degree of freedom; $\mathrm{P}=0.436(\mathrm{NS})$ 


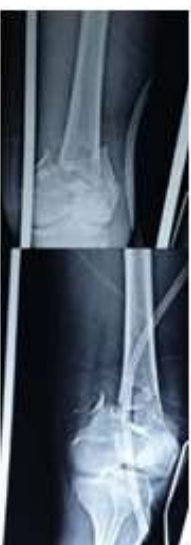

Pre-op X-ray.

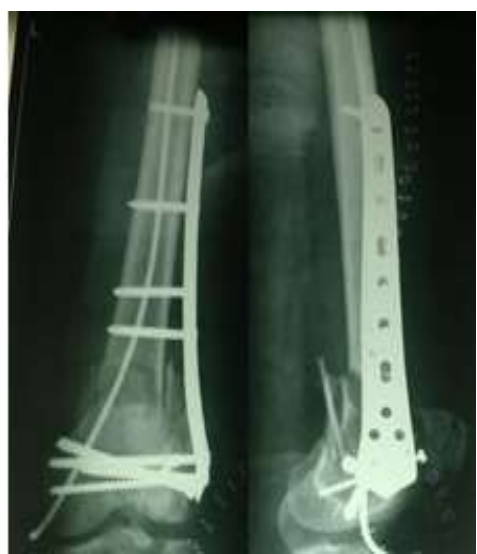

Post-op X-ray

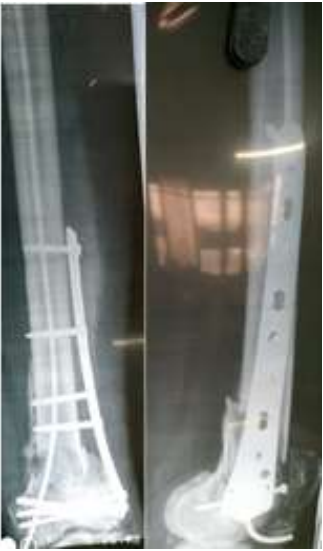

At 3 months follow up.

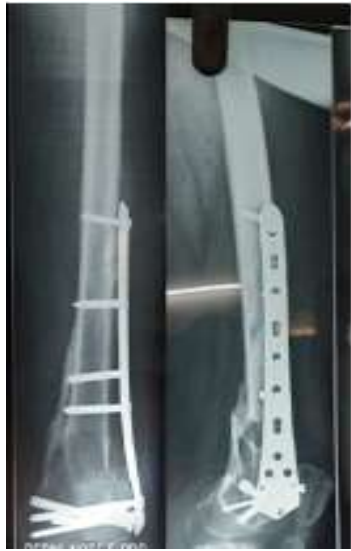

At 6 months follow up

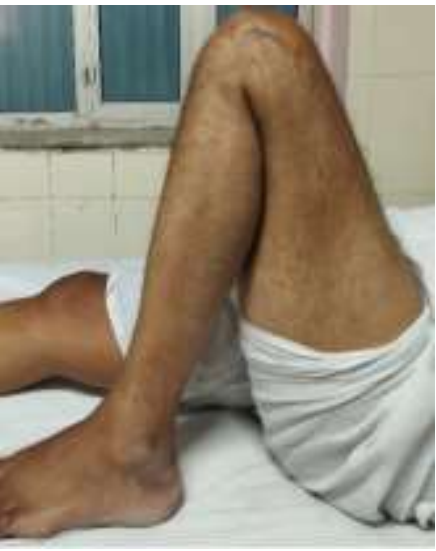

At 6 months follow up

Fig 1: A 27 years old patient having H/O RTA had \# Lt. Supra condylar femur type C3 fixed with DFLCP and TENS nail

\section{Discussion}

Mongkon Luechoowong (2008) analysed retrospectively medical records of 19 patients who underwent LCP plating for complex distal femoral fractures and reported higher incidence in males than females and the mean age in the study was 41.6 years ${ }^{[7]}$.

In our study of 80 patients the mean age of the patients was 39.08 years and there were 66 males $(82.5 \%)$ and 14 females $(17.5 \%)$. This is a reflection of the mechanism of injury which was high energy trauma in $91.3 \%$ of our patients of which most of whom were younger.

The reason being that, in male patients there was more outdoor activities, so they were more prone to vehicular accident and majority females being house wives were less exposed to road traffic accidents.

In our study most of the injuries were caused by road traffic accidents affecting mostly males. We had 73 (91.3\%) RTA injuries and $7(8.7 \%)$ Fall from height and other. There were no sports or industrial accidents.

Weight $\mathrm{M}$, et al (2004) reported incidence of RTA in 18 $(82 \%)$ patients than falls in $4(18 \%)^{[8]}$.

This signifies that most of the distal femoral fractures are caused by Road Traffic Accidents.

The distal femoral fractures has been classified by Muller (AO) into extra-articular, partial articular and intraarticular types. We have based our study on intraarticular type C fractures which are generally associated with severe comminution and bony loss.

The side distribution in this study showed marginally more number of persons with fractures on the right side than on the left in our study, 55\% patients had right femur involvement and $45 \%$ had left femur involvement. Most patients were operated with 3 to 7 days. Post operatively physiotherapy in bed was started on the 2 nd post

operative day or according to the tolerance of patient and associated injuries. The patients were started with quadriceps strengthening exercises, calf exercises, knee and ankle mobilization exercises. Partial weight bearing was started after 7 to 9 weeks in most of the cases where fixation was done with DFLCP with TENS nail and 10 to 12 weeks in most of the cases where fixation done with DFLCP. Full weight bearing was started according to signs of union on follow up. P Kanabar, et al (2007) early partial weight bearing was allowed under supervision of the physiotherapist. Full weight bearing was started depending on the clinical and radiological progress of fracture healing ${ }^{[9]}$.

Based on above finding we conclude that physiotherapy and rehabilitation have important role to play in restoring maximal functional outcome. Physiotherapy should be started on second post operative day and partial weight bearing at 7 week-3 months. Full weight bearing should be started when radiological union is apparent.

Successful fracture union was defined as complete bridging callus in three cortices, together with painless full weight bearing. Radiological union of the fracture i.e. characterized by cortex to cortex healing and bridging callus of the fracture in both AP and lateral views of follow up x-rays, was considered as satisfactory union. In our study time of union and weight bearing was delayed where intra -articular comunition present in distal femur (C1-C3). In our study in DFLCP with TENS nail group $78.9 \%$ fractures were united in $<15$ to 20 weeks and in DFLCP group $56.7 \%$ fractures were united in $<15$ to 20 weeks. Average time to Union was 17.7 weeks in DFLCP with TENS nail group and 19.9 weeks in DFLCP group. $100 \%$ union rate was seen in DFLCP with TENS nail group and $91.9 \%$ union rate was seen in DFLCP group. There was no significant difference in union time in our study.

GN Kiran Kumaret al (2014) evaluated functional outcome, fracture healing, and the complications of distal femoral intraarticular fractures using locking compression plates. They reviewed 46 distal femoral fractures treated with distal femoral locking compression plates. The mean time for radiological union was 12 weeks (range 10-18) except 2 patients which had gone for nonunion ${ }^{[10]}$.

We concluded that time to union in distal femoral intercondylar fracture was generally longer than usual fracture union due to high incidence of communition.

In our study six of the patient had infection. 3 patients were from DFLCP group, treated with antibiotics, wasn't require second surgery.

3 patients from DFLCP with TENS nail group. Serous discharge was from TENS nail entry site that was treated with antibiotics. In 2 patients Discharge stopped after tens nail removed earlier than 2 months after operation and antibiotics given. In One patient antibiotics was given only.

There were three cases of non-union where fixation done with DFLCP. No case of non-union was seen in DFLCP with TENS nail group probably due to additional stability was provided by TENS nail. In 2 patients bone grafting is done and fracture was united 13 weeks after second operation. In one patient masquelet then bone grafting was done. In this patient fracture union time was 16 weeks after second surgery.

Manish Singh et al (2016) reported that varus angulation occurs with defect is decreased with use of TENS nail for 
medial femoral defect along with condylar buttress plate ${ }^{[11]}$. In our study we had three cases of varus mal-alignment for distal femur in DFLCP with TENS nail group and eleven cases of varus mal-alignment for distal femur in DFLCP group and we found a significant difference in varus angulation in our study group.

In our study shortening was $<2 \mathrm{~cm}$ seen in 9 out of 38 patients in DFLCP with TENS nail group and there was 19 patients out of 37 patients had shortening $<2 \mathrm{~cm}$ and 3 patients had shortening $>2 \mathrm{~cm}$ in DFLCP group Out of 38 patients 25 patients $(65.8 \%)$ patients had flexion between 110 to 130 degree at final follow up in DFLCP with TENS nail group and out of 37 patients in DFLCP group at final follow up 19 patients $(51.3 \%)$ had flexion between 110 to 130 degree. 5 patients out of 38 had range of motion > 130 degree in DFLCP with TENS nail group and 4 out of 37 patients had range of motion $>130$ degree in DFLCP group. In our study range of motion at knee joint was limited initially in DFLCP and TENS nail group, that was increased after TENS nail removal when union started. The initial limitation in range of movement was probably due to hindrance provided by TENS nail during knee movement..

In our study we had used schatzker and lambert score for functional outcome. Out of 38 patients in DFLCP with TENS group 11 cases $(28.9 \%)$ had excellent, 17 cases $(44.7 \%)$ had good, 9 cases $(23.7 \%)$ had fair, 1 case $(2.7 \%)$ had poor outcomes.

Out of 37 patients in DFLCP group 9 cases (24.3\%) had excellent, 13 cases $(35.1 \%)$ had good, 11 cases $(29.8 \%)$ had fair and 4 cases $(10.8 \%)$ had poor outcomes.

\section{Limitations}

Our study was single centre study. Had it been multicentric study results would reflect wider range of trauma at different trauma centres. Sample size of our study was small

Follow up period was relatively short as the osteoarthritis related complications take 2-3 years to develop.

\section{Conclusion}

We have based our study on intraarticular type $C$ fractures which are generally associated with severe comminution and bony loss. In intercondylar fractures, there will be rotational mal-alignment because of separate attachments of gastrocnemius muscle to each condyle.

Complications of distal femoral fractures include malunion, nonunion, varus angulation, limb length discrepancy, infections and secondary osteoarthritis of patellofemoral and tibiofemoral joints.

These fractures earlier treated non-surgically were associated with angular deformity, joint incongruity, knee stiffness and delayed patient mobilisation.

Locking plate systems such as the LISS (Less Invasive Stabilising System) have been extensively used for distal femoral fractures. Dual plating used in comminuted fractures often result in extensive soft tissue stripping on both sides of femur resulting in reduced blood supply, delayed or nonunion and failure of implant. Callus formation was inconsistent and irregular with these plates. The use of TENS nail for medial femoral defect along with DFLCP may eliminate the need of plate on medial side. The varus angulation that occurs with defect is decreased and additional long incision and operative time is avoided. By conducting this study we can put forward the assumption with some degree of confidence that fractures of the distal femur of type $\mathrm{C}$ of the AO classification, if fixed with DFLCP with TENS nail then chances of varus angulation will be less.

\section{References}

1. Shah S, Bhalodia R, Kalaria P et al. Study of distal femoral fractures ISSN: 2229-3809 (Online) Journal DOI:10.7439

2. Muller ME, Appendix A. the comprehensive classification of fractures of long bones. In: Muller ME, Allgower M, Schneider R, Willenegger H, eds. Manual of Internal Fixation. 3rd ed. New York, NY: Springer 1991, 118-150

3. Kregor PJ, Stannard J, Zlowodzki M, Cole PA, Alonso J. Distal femoral fracture fixation utilizing the Less Invasive Stabilization System (L.I.S.S.): the technique and early results. Injury 2001;32(3):SC32-SC47.

4. Gwathmey FW, Jones-Quaidoo SM, Kahler D, Hurwitz S, Cui Q. Distal femoral fractures: current concepts. J Am Acad Orthop Surg 2010;18:597-607.

5. Nasr AM, Mc Leod I, Sabboubeh A, Maffulli N. Conservative or surgical management of distal femoral fractures. A retrospective study with a minimum five year follow-up. Acta Orthop Belg. 2000;66:477-483.

6. Schandelmaier P, Partenheimer A, Koenemann B, Grün OA, Krettek C. Distal femoral fractures and LISS stabilization. Injury. 2001;32(3):SC55-63.

7. Mongkon Luechoowong. The Locking Compression Plate (LCP) for Distal Femoral Fractures. Buddhachinaraj Medical journal 2008;25 (1).

8. Weight M, Collinge C. Early results of the L.I.S.S for mechanically unstable fracture of the distal femur (AO/OTA type A2, A3, C2 AND C3) J Orthop Trauma. 2004;18(8):503-8

9. Kanabar P, Kumar V, Owen PJ. Less invasive stabilisation system plating for distal femoral fractures, Journal of Orthopaedic Surgery 2007;15(3):299-302.

10. Kiran Kumar GN et al. Locking Compression Plate in Distal Femoral Intra-Articular Fractures: Our Experience 2014, Article ID 372916, 5 pages.

11. Manish Singh, Shafiq Halqa, Mohinder Singh Chib. Outcome Of Bicolumnar Fixation of Intercondylar Femur Fracture With Condylar Buttress Plate and TENS(titanium elastic nails) Nail 2016;18(3) 